\title{
Novel dichloromethane-fermenting bacteria in the Peptococcaceae family
}

\author{
Sophie I. Holland $\mathbb{D}^{1} \cdot$ Haluk Ertan ${ }^{2,3} \cdot$ Kate Montgomery ${ }^{4} \cdot$ Michael J. Manefield $\left(\mathbb{D}^{1,3} \cdot\right.$ Matthew Lee ${ }^{1}{ }^{1}$
}

Received: 18 August 2020 / Revised: 29 November 2020 / Accepted: 9 December 2020 / Published online: 15 January 2021

(c) The Author(s) 2021. This article is published with open access

\begin{abstract}
Dichloromethane (DCM; $\mathrm{CH}_{2} \mathrm{Cl}_{2}$ ) is a toxic groundwater pollutant that also has a detrimental effect on atmospheric ozone levels. As a dense non-aqueous phase liquid, DCM migrates vertically through groundwater to low redox zones, yet information on anaerobic microbial DCM transformation remains scarce due to a lack of cultured organisms. We report here the characterisation of DCMF, the dominant organism in an anaerobic enrichment culture (DFE) capable of fermenting DCM to the environmentally benign product acetate. Stable carbon isotope experiments demonstrated that the organism assimilated carbon from DCM and bicarbonate via the Wood-Ljungdahl pathway. DCMF is the first anaerobic DCMdegrading population also shown to metabolise non-chlorinated substrates. It appears to be a methylotroph utilising the Wood-Ljungdahl pathway for metabolism of methyl groups from methanol, choline, and glycine betaine. The flux of these substrates from subsurface environments may either directly (DCM, methanol) or indirectly (choline, glycine betaine) affect the climate. Community profiling and cultivation of cohabiting taxa in culture DFE without DCMF suggest that DCMF is the sole organism in this culture responsible for substrate metabolism, while the cohabitants persist via necromass recycling. Genomic and physiological evidence support placement of DCMF in a novel genus within the Peptococcaceae family, 'Candidatus Formimonas warabiya'.
\end{abstract}

\section{Introduction}

Dichloromethane (DCM, $\mathrm{CH}_{2} \mathrm{Cl}_{2}$ ) is one of the most commonly encountered subsurface pollutants in industrial areas [1]. Current global production of DCM exceeds 900 $\mathrm{Gg}^{-1}$, of which $70 \%$ is manufactured by humans [2].

Supplementary information The online version of this article (https:// doi.org/10.1038/s41396-020-00881-y) contains supplementary material, which is available to authorized users.

Matthew Lee

mattlee@unsw.edu.au

1 Water Research Centre, School of Civil and Environmental Engineering, University of New South Wales, Sydney, NSW, Australia

2 Department of Molecular Biology and Genetics, Istanbul University, Istanbul, Turkey

3 School of Chemical Engineering, University of New South Wales, Sydney, NSW, Australia

4 School of Biotechnology and Biomolecular Sciences, University of New South Wales, Sydney, NSW, Australia
The remaining $30 \%$ comes from natural sources including biomass burning, oceanic sources, and geothermal activity [2]. Due to widespread production and use of DCM, both surface and tropospheric levels of this toxic chemical continue to rise [3-6]. Atmospherically, DCM has recently been recognised as a potent greenhouse gas with detrimental effects on ozone [7]. The compound also poses a threat to human health $[8,9]$ and microbial function [10-12].

Nonetheless, microbial transformation of DCM is an option for remediation of oxic and anoxic environments. Aerobic DCM transformation is catalysed by a DCM dehalogenase found in facultative methylotrophs [13, 14], but the enzyme responsible for anaerobic DCM dechlorination has not yet been identified. DCM is a dense nonaqueous phase liquid that descends through groundwater to low redox zones, and so anaerobic degradation plays a vital role in its removal from contaminated sites. Yet study of anaerobic DCM degradation has been hindered by the limited number of organisms capable of this metabolism. Dehalobacterium formicoaceticum strain DMC is the only isolate [15] and from the handful of enrichment cultures [16-18], only 'Candidatus Dichloromethanomonas 
elyunquensis' strain RM has been characterised [19, 20]. Both $\mathrm{D}$. formicoaceticum and ' $\mathrm{Ca}$. Dichloromethanomonas elyunquensis' are obligate anaerobic DCM-degrading bacteria and have genome sequences available [15, 19, 21, 22]. A combination of genomic, physiological, and proteomic work has demonstrated the central role of the Wood-Ljungdahl pathway (WLP) in DCM metabolism in both organisms, however variations on the pathway result in different end products $[15,20,23]$. D. formicoaceticum ferments DCM to formate and acetate in a 2:1 molar ratio [15], whilst ' $\mathrm{Ca}$. Dichloromethanomonas elyunquensis' completely mineralises DCM to $\mathrm{H}_{2}$ and $\mathrm{CO}_{2}$ [23].

The subject of this work is a new anaerobic DCM-degrading lineage, referred to as "DCMF", that is the dominant organism in a previously reported nonmethanogenic bacterial enrichment culture, designated culture DFE [24]. The community was enriched from an organochlorine-contaminated aquifer near Botany Bay, Sydney, Australia and culture DFE has been maintained on DCM as the sole energy source [24]. The culture was recently subjected to PacBio sequencing and the $6.4 \mathrm{Mb}$, gap-free DCMF genome encoded a complete WLP [24]. However, genome-based metabolic modelling suggested that DCMF may have a wider substrate repertoire due to the presence of 81 full-length MttB superfamily methyltransferases that could confer ability to utilise methylated amines and glycine/betaine/sarcosine reductase gene clusters [24].

Here, we report that DCMF is the first non-obligate anaerobic DCM-degrading bacterium and characterise its metabolism of DCM, quaternary amines, and methanol, whilst also considering the role of the cohabiting bacteria in culture DFE. Stable carbon isotope labelling was used to determine the fate of DCM carbon and function of the WLP. Based on its genomic and physiological novelty, DCMF is proposed to form a novel genus within the Peptococcaceae family. Using contemporary molecular and traditional cultivation techniques, this study represents a thorough and robust characterisation of a novel bacterium despite its presence in a multi-lineage enrichment culture.

\section{Materials and methods}

\section{Culture medium}

Culture DFE was grown in anaerobic, defined bicarbonatebuffered mineral salts medium as previously described [24]. To investigate the requirement for exogenous bicarbonate during DCM degradation, cultures were instead buffered with 3-morpholinopropane-1-sulfonic acid (MOPS, $4.2 \mathrm{gl}^{-1}$ ), either with or without $4 \mathrm{mM} \mathrm{NaHCO}_{3}$. To study the metabolic fate of DCM, ${ }^{13} \mathrm{C}$-labelled DCM $\left(\left[{ }^{13} \mathrm{C}\right] \mathrm{DCM}\right.$, $1 \mathrm{mM}$ ) was used. To study the assimilation of inorganic carbon, ${ }^{13} \mathrm{C}$-labelled bicarbonate $\left(\mathrm{NaH}^{13} \mathrm{CO}_{3}, 5 \mathrm{mM}\right)$ was added to MOPS-buffered culture medium.

To test alternative growth substrates, DCM was replaced with the following ( $5 \mathrm{mM}$ unless stated otherwise): carbon monoxide $(2 \mathrm{mM})$, choline chloride, dibromomethane, dimethylglycine, formic acid, $\mathrm{H}_{2}$, glycine betaine, methanol, sarcosine, syringic acid, trimethylamine. Cultures amended with choline chloride, glycine betaine, and trimethylamine were also amended with the following compounds as electron acceptors $(15 \mathrm{mM}$ unless otherwise stated): fumarate ( $80 \mathrm{mM}$, tested with trimethylamine only), $\mathrm{NaNO}_{2}, \mathrm{NaNO}_{3}, \mathrm{Na}_{2} \mathrm{SO}_{3}$ and $\mathrm{Na}_{2} \mathrm{SO}_{4}$. Acetate, $\mathrm{H}_{2}$, and lactate were tested as electron donors with $\mathrm{Na}_{2} \mathrm{SO}_{3}$ and $\mathrm{Na}_{2} \mathrm{SO}_{4}$ as electron acceptors. Glycine betaine and sarcosine $(5 \mathrm{mM})$ were tested as electron acceptors with $\mathrm{H}_{2}(10 \mathrm{mM})$ as electron donor.

\section{Analytical methods}

DCM, dibromomethane, acetate, formate, methanol, and trimethylamine were quantified using a Shimadzu Plus GC2010 gas chromatograph with flame ionisation detector equipped with a headspace autosampler (PAL LHS2-xtShim; Shimadzu, Rydalmere, Australia; Table S1). $\mathrm{HCO}_{3}{ }^{-}$ (as gaseous $\mathrm{CO}_{2}$ ) and $\mathrm{H}_{2}$ were quantified using a Shimadzu GC-2010 gas chromatograph with pulsed discharge detector (Table S1). In all analyses, the inlet temperature was $250^{\circ}$ C, split ratio $1: 10$, FID temperature $250^{\circ} \mathrm{C}$ or PDD temperature $150{ }^{\circ} \mathrm{C}$.

Choline and glycine betaine were quantified using liquid chromatography with tandem mass spectrometry. The Agilent 1200 Series LC (Agilent Technologies, Mulgrave, Australia) was fitted with a Luna C18 (2) column $(150 \times 4.6 \mathrm{~mm}, 5 \mu \mathrm{m}$; Phenomenex, Lane Cove West, Australia). The mobile phases were $0.5 \mathrm{mM}$ ammonium acetate in water (A) and $100 \%$ methanol (B). Samples $(5 \mu \mathrm{l})$ were eluted with a linear gradient from $95: 5(\mathrm{~A}: \mathrm{B})$ to $0: 100(\mathrm{~A}: \mathrm{B})$ over $10 \mathrm{~min}$, then held at 0:100 (A:B) for $1 \mathrm{~min}$. The $\mathrm{LC}$ was coupled to an Applied Biosystems QTRAP 4000 quadrupole mass spectrometer (SCIEX, Mulgrave, Australia) and electrospray ionisation performed in the positive mode. The machine was operated in multiple reaction monitoring (MRM) mode and the following precursor-product ion transitions were used for quantification: $\mathrm{m} / \mathrm{z} 104.0 \rightarrow 59.0$ (choline) and $\mathrm{m} / \mathrm{z}$ $118.0 \rightarrow 57.7$ (glycine betaine).

Labelled and unlabelled acetate, $\mathrm{CO}_{2}$, and $\mathrm{HCO}_{3}{ }^{-}$were quantified via $\mathrm{GC}$ with triple quadrupole mass spectrometry (GC-TQMS) performed with an Agilent 7890 A GC system (Table S1). The TQMS was operated in MRM mode identifying the following precursor-product ion transitions: $m / z, 43 \rightarrow 15.2$ (unlabelled acetate), $m / z 44 \rightarrow 15.1\left(\left[1-{ }^{13} \mathrm{C}\right]\right.$ 
acetate), $m / z 44 \rightarrow 16$ ([2- $\left.{ }^{13} \mathrm{C}\right]$ acetate $), m / z 45 \rightarrow 16.1$ ([1,2${ }^{13}$ C]acetate $), m / z, 45 \rightarrow 29\left({ }^{13} \mathrm{CO}_{2}\right), m / z, 44 \rightarrow 28\left({ }^{12} \mathrm{CO}_{2}\right)$.

GC-TQMS in MRM mode was also used to quantify dimethylamine, monomethylamine, sarcosine, and glycine, using alanine as an internal standard. Following derivatisation [25] (Table S1), the following precursorproduct ion transitions were used: $\mathrm{m} / \mathrm{z} 117.2 \rightarrow 89.1$ (dimethylamine), $\mathrm{m} / \mathrm{z} .103 .2 \rightarrow 74.9$ (monomethylamine), $\mathrm{m} / \mathrm{z} .116 .2 \rightarrow 44.1$ (sarcosine and alanine), and $102 \rightarrow 30.1$ (glycine).

\section{Bacterial quantification}

Genomic DNA was extracted from $2 \mathrm{ml}$ liquid culture as previously described [24]. DCMF and total bacterial $16 \mathrm{~S}$ rRNA genes were quantified via quantitative real-time PCR (qPCR) with primers Dcm775/Dcm930 and Eub1048/ Eub1194 [26], respectively (Table S2). Standard curves were prepared by making serial tenfold dilutions of plasmid DNA carrying cloned DCMF 16S rRNA or Dehalococcoides sp. 16S rRNA (for total bacterial quantification). Reactions were carried out on a CFX96 thermal cycler (Bio-Rad, Gladesville, Australia) and the data was analysed with CFX Maestro v1.0 software (Bio-Rad). DCMF 16S rRNA gene copy numbers were converted to cell numbers by dividing by four (the number of 16S rRNA genes in the genome).

\section{$16 S$ rRNA gene amplicon sequencing}

Community profiling was carried out on the above DNA samples. The 16S rRNA gene was amplified with the $515 \mathrm{~F} /$ $806 \mathrm{R}$ primer pair with adapters (Table S2). Samples were sequenced with Illumina MiSeq technology by The Hawkesbury Institute for the Environment Next Generation Sequencing Facility. Amplicon reads were processed in QIIME2 [27] using the dada2 pipeline [28]: forward and reverse reads were trimmed and joined, chimeras were removed, and samples were rarefied to the lowest sequencing depth. Taxonomy was assigned to genus level using a Naïve Bayes classifier trained on a full-length 16S rRNA gene SILVA database (release 133) and the lowest $1 \%$ abundant reads were filtered out. Alpha diversity was assessed with Shannon's diversity index and pairwise comparisons made with a Kruskal-Wallis test. A two-dimensional PCA plot was created from the weighted Unifrac distance matrix. Samples were compared by the stage of substrate consumption, as well as timepoint, to account for differing metabolic rates between substrates (Table S3).

\section{Cultivation of DFE cohabitant bacteria}

To eliminate DCMF and enrich the cohabiting bacteria in culture DFE, two rounds of dilution to extinction cultures
$(20 \mathrm{ml})$ were set up in $30 \mathrm{ml}$ glass serum bottles (Fig. S1). These were prepared with the standard medium amended with one of: casamino acids $\left(5 \mathrm{gl}^{-1}\right)$, ethanol $(10 \mathrm{mM})$, glucose $(10 \mathrm{mM})$, peptone $\left(5 \mathrm{~g} \mathrm{l}^{-1}\right)$, 1-propanol $(10 \mathrm{mM})$, yeast extract $\left(5 \mathrm{gl}^{-1}\right)$. Following qPCR confirmation that the DCMF 16S rRNA gene was below the limit of detection in the lowest active dilution culture, these cultures were subject to Illumina 16 rRNA gene amplicon sequencing and used to inoculate triplicate microcosms amended with one of: $1 \mathrm{mM}$ DCM, $5 \mathrm{mM}$ choline chloride, or $5 \mathrm{mM}$ glycine betaine (Fig. S1), which were monitored for 8 weeks.

\section{Fluorescence in situ hybridisation microscopy}

Fluorescence in situ hybridisation (FISH) was carried out with a DCMF-specific oligonucleotide probe (Dcm623, 5'-/Cy3/CTCAAGTGCCATCTCCGA-3'), designed using ARB [29], and probe Eub338i (5'-/6-FAM/GCTGCCTCCC GTAGGAGT-3') [30] to target all bacteria. FISH was carried out as per an established protocol for fixation on a polycarbonate membrane, using minimal volumes of reagents [31]. Cells were fixed with protocols for both Gram-negative [30] and Gram-positive cell walls [32]. Hybridisation was carried out with a formamide-free buffer. Cells were counterstained with VECTASHIELD ${ }^{\circ}$ Antifade Mounting Medium containing $1.5 \mu \mathrm{g} \mathrm{ml}^{-1}$ 4,6-diamidino-2-phenylindole (Vector Laboratories, Burlingame, CA, USA). Images were captured on a BX61 microscope equipped with a DP80 camera (Olympus Australia, Notting Hill, Australia) using Olympus cellSens Dimension software v2.1. DCMF cell length and width was determined from a sample of 20 cells using the linear measurement tool within the programme.

\section{Phylogenetic analysis of DCMF}

Whole genome taxonomic analysis of DCMF was carried out with the GTDB-Tk (Genome Taxonomy Database toolkit) [33]. The average nucleotide identity (ANI) tool from the Kostas lab [34] was used to calculate ANI values between DCMF and D. formicoaceticum strain DMC. CompareM (https://github.com/dparks1134/CompareM) was used to calculate the two-way average amino acid identity (AAI) between the anaerobic DCM degraders and other related bacteria in the family Peptococcaceae.

\section{Results}

\section{Dichloromethane fermentation}

After a 21 day lag period, culture DFE consumed DCM at a rate of $133 \pm 3 \mu \mathrm{M}$ day $^{-1}$, yielding $2.0 \pm 1.2 \times 10^{14} \mathrm{DCMF}$ cells per mole of substrate consumed (Fig. 1A). The product 

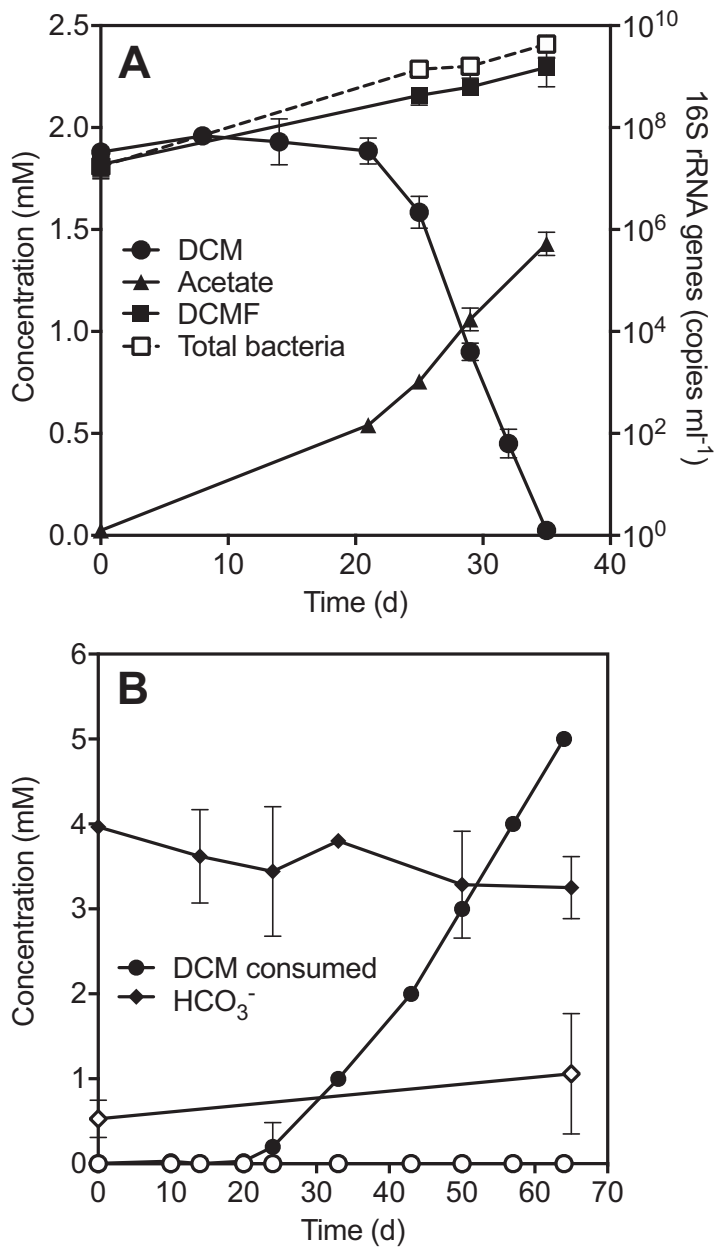

Fig. 1 DCM degradation by culture DFE. A DCMF growth was concomitant with the depletion of DCM and formation of acetate. Substrate and product concentrations are quantified on the left $y$-axis; DCMF and total bacterial 16S rRNA gene copies are quantified on the right $y$-axis. Error bars represent standard deviation, $n=2$. B In MOPS-buffered medium, DCM consumption was only observed in the presence of bicarbonate (filled circles). Cumulative DCM consumption is from repeat amendment of $1 \mathrm{mM}$ DCM. Empty circles represent cultures with no exogenous bicarbonate. Error bars represent standard deviation, $n=3$.

of DCM fermentation was acetate $(0.76 \pm 0.03 \mathrm{~mol}$ per mole DCM consumed), which was not observed in abiotic controls. DCM attenuation did not proceed in MOPS-buffered cultures free of bicarbonate (Fig. 1B). However, in analogous cultures amended with $4 \mathrm{mM} \mathrm{NaHCO}_{3}, \mathrm{DCM}$ attenuation was observed, yet $\mathrm{HCO}_{3}{ }^{-}$concentrations did not significantly change ( $p=0.11$, two-tailed $t$-test between days 0 and 65; Fig. 1B).

\section{Metabolism of methanol and quaternary amines}

Of the additional substrates tested as sole energy source or with an electron acceptor, DCMF growth was observed when methanol, choline or glycine betaine $(5 \mathrm{mM}$ each) were supplied (Fig. 2). Culture DFE consumed methanol at a rate of $309 \pm 31 \mu \mathrm{M}$ day $^{-1}$ after a 14 day lag period, yielding $0.74 \pm 0.04 \mathrm{~mol}$ acetate and $5.7 \pm 1.4 \times 10^{14} \mathrm{DCMF}$ cells per mole substrate utilised (Fig. 2A). No methanol depletion was observed in the abiotic (cell-free) control.

Culture DFE consumed choline at a rate of $344 \pm 68 \mu \mathrm{M}$ day $^{-1}$ after an 11 day lag period, producing $3.1 \pm 0.13 \mathrm{~mol}$ acetate and $1.3 \pm 0.24 \mathrm{~mol}$ monomethylamine per mole choline utilised (Fig. 2B). The culture also consumed glycine betaine at a rate of $328 \pm 26 \mu \mathrm{M}$ day $^{-1}$ after a 7 day lag period, producing $2.3 \pm 0.08 \mathrm{~mol}$ acetate and $0.95 \pm 0.13 \mathrm{~mol}$ monomethylamine per mole glycine betaine utilised (Fig. 2C). Trimethylamine, dimethylamine, sarcosine (methylglycine), and glycine were not detectable throughout. Neither acetate nor monomethylamine were detected in abiotic controls, and the latter was also absent from cultures amended with DCM. DCMF cell proliferation aligned with the consumption of these two substrates, yielding an increase $3.0 \pm 0.9 \times 10^{14}$ cells per mole of choline and $1.1 \pm 0.1 \times 10^{14}$ cells per mole of glycine betaine utilised (Fig. 2B, C).

DFE cultures amended with quaternary amine metabolic pathway intermediates dimethylglycine and sarcosine $\left(+\mathrm{H}_{2}\right)$ also demonstrated production of acetate and monomethylamine, which again aligned with DCMF cell proliferation (Fig. S2). Sarcosine was not degraded in the absence of $\mathrm{H}_{2}$ (data not shown). Following the observation of DCMF growth and monomethylamine production in cultures amended with sarcosine $+\mathrm{H}_{2}$, DFE cultures were also set up with glycine betaine $+\mathrm{H}_{2}$ to determine whether glycine betaine could be reductively cleaved to trimethylamine and acetate. These cultures consumed all glycine betaine $(4.4 \pm 0.4 \mathrm{mM})$ and hydrogen $(7.9 \pm 0.9 \mathrm{mM})$ within 28 days, producing $15 \pm$ $0.6 \mathrm{mM}$ acetate and $5.5 \pm 0.6 \mathrm{mM}$ monomethylamine, but no trimethylamine (Fig. 2D). DCMF cell yields (4.0 \pm $2.8 \times 10^{8}$ cells $\mathrm{ml}^{-1}$ ) were similar to that when glycine betaine was the sole energy source.

Culture DFE was unable to utilise CO, dibromomethane, ethanol, formic acid, syringic acid or trimethylamine as sole energy sources (no growth and/or acetogenesis observed). DCMF was further unable to use any of the tested pairs of electron donors (acetate, choline, glycine betaine, $\mathrm{H}_{2}$, lactate, trimethylamine) and acceptors $\left(\mathrm{CO}_{2}\right.$, fumarate, $\mathrm{Na}_{2} \mathrm{SO}_{4}, \mathrm{Na}_{2} \mathrm{SO}_{3}, \mathrm{NaNO}_{2}$, and $\mathrm{NaNO}_{3}$ ).

\section{Shifts in DFE community composition in response to substrate consumption}

Community profiling with Illumina $16 \mathrm{~S}$ rRNA gene amplicon sequencing showed that culture DFE is composed of a limited number of taxa-only 12 amplicon sequencing variants (ASVs) were present at $\geq 2 \%$ relative abundance in $>1$ sample (Fig. 3). Community composition was similar 

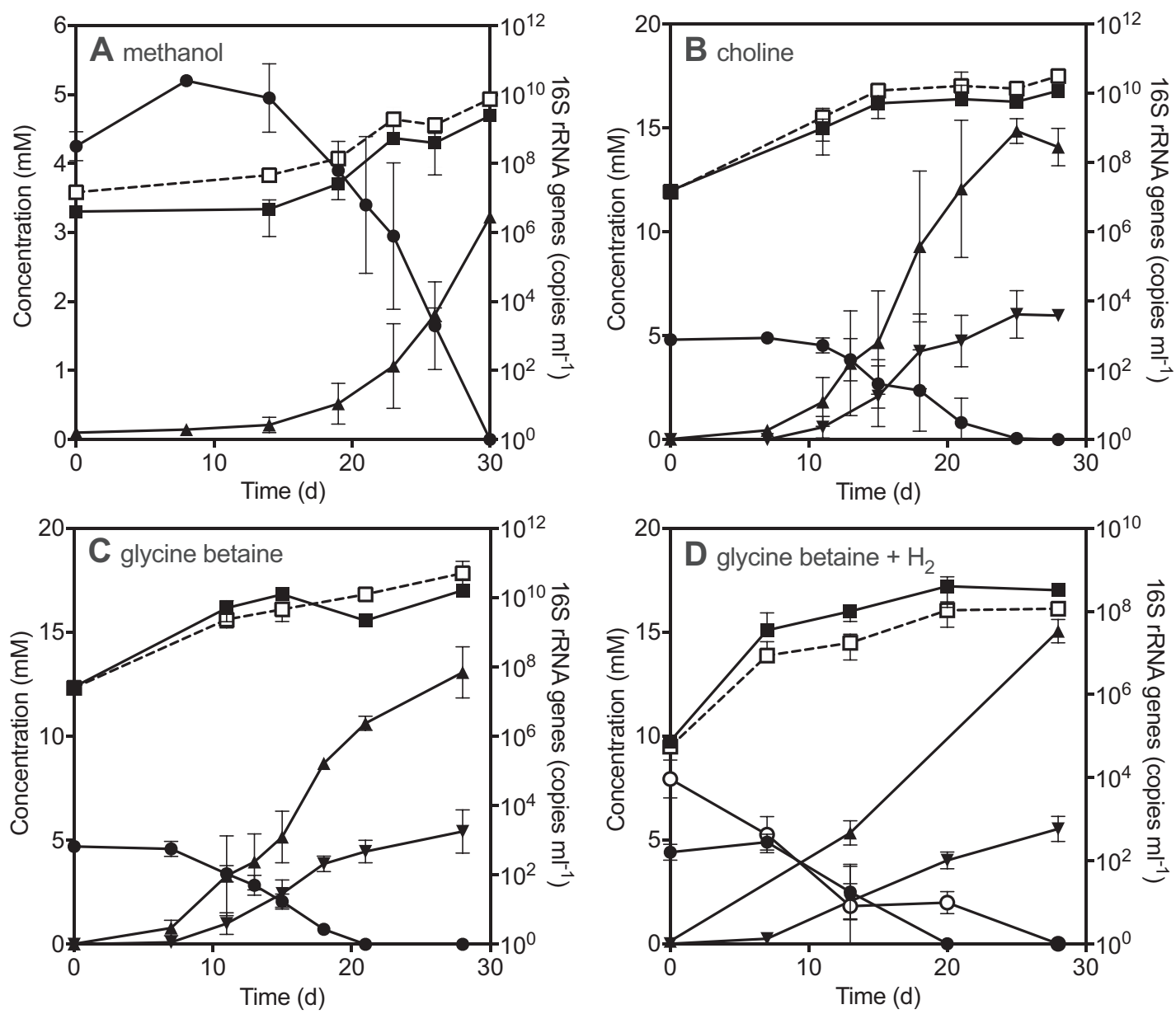

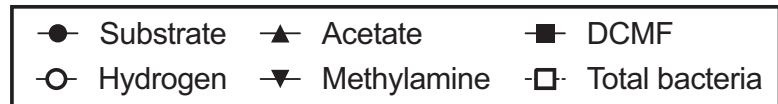

Fig. 2 Degradation of methanol and quaternary amines by culture DFE. DCMF growth correlated with the depletion of methanol and formation of acetate (A) and the depletion of choline (B) and glycine betaine $(\mathbf{C})$ with formation of acetate and monomethylamine. Cultures amended with glycine betaine and hydrogen (D) did not produce

in cultures amended with DCM, choline, and glycine betaine, which had a common, DCM-amended inoculum (Fig. 3A-C), but was simplified in cultures that had been maintained on methanol for two sub-cultivations and had a methanol-amended inoculum (Fig. 3D; Fig. S3A). While DCMF was the dominant organism at the time of inoculation and during substrate consumption, its relative abundance decreased markedly in the lag phase prior to substrate consumption, falling to as little as $0.96 \%$ in a methanolamended replicate at day 14 (Fig. 3). Taxa such as Synergistaceae (except in methanol-amended cultures, where this taxon was absent), Desulfovibrio and Veillonellaceae increased in relative abundance during this lag phase, while Spirochaetaceae and Lentimicrobiaceae increased towards the end of and following substrate depletion, particularly in quaternary amine-amended cultures (Fig. 3). trimethylamine, rather acetate and monomethylamine were once again the products. Substrate and product concentrations are quantified on the left $y$-axis; DCMF and total bacterial 16S rRNA gene copies are quantified on the right $y$-axis. Error bars represent standard deviation, $n=3$.

Differences in the DFE community were driven by the degree of substrate consumption (defined in Table S3), more than the various substrates (Fig. S3B). While there was no significant difference in the Shannon diversity index between the samples when grouped by substrate (Kruskal-Wallis $p$ value 0.0976; Fig. S3C), there was a highly significant difference between all groups when clustered by degree of substrate consumption (Kruskal-Wallis $p$ value $<0.00001$; Fig. S3D).

\section{Exclusion of cohabitants as DCM and quaternary amine consumers}

Attempts to isolate DCMF proved unsuccessful [24]. Therefore, to test the hypothesis that DCMF was the sole consumer of DCM and quaternary amines, the cohabiting bacteria in 

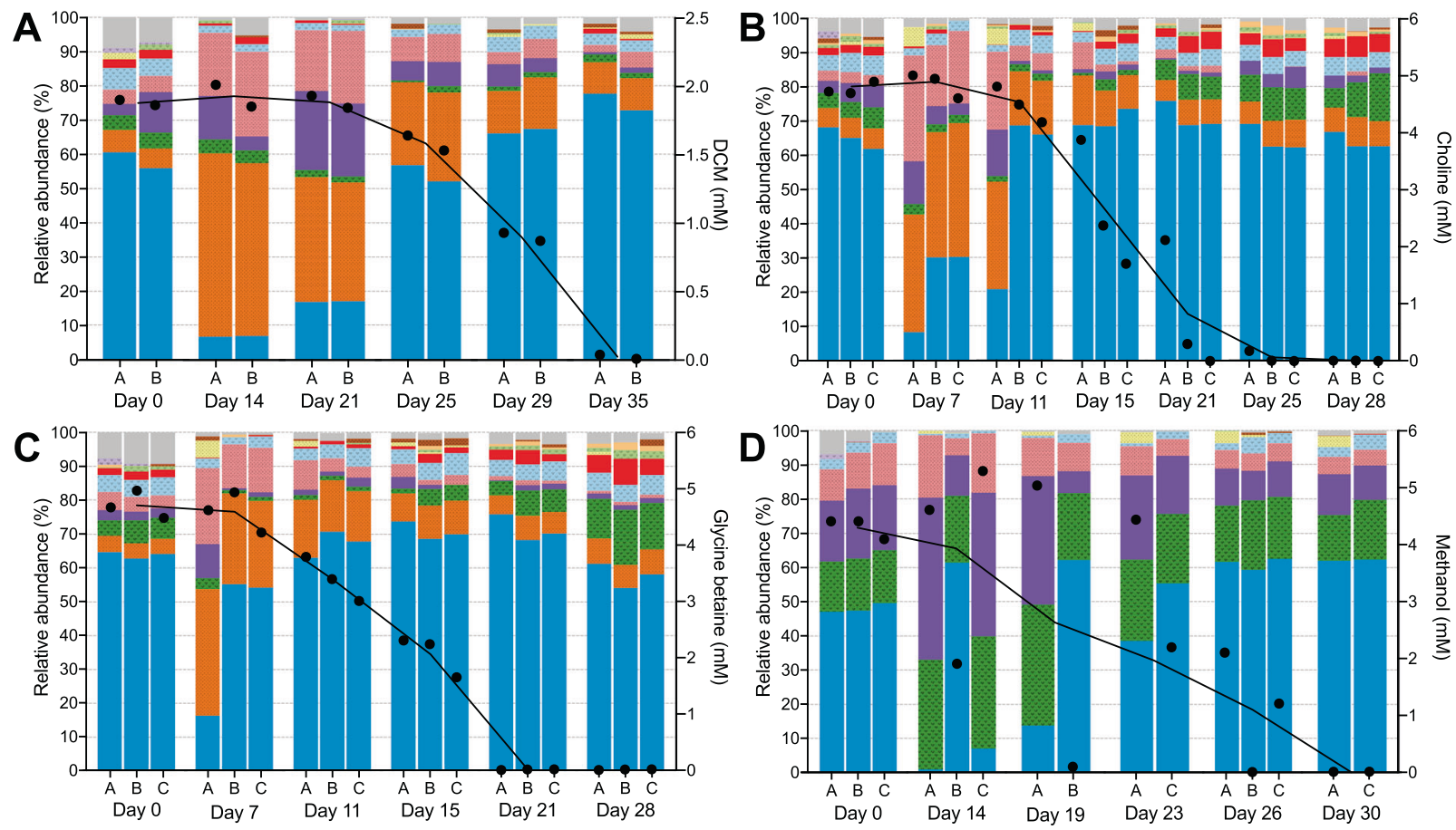

\begin{tabular}{|lll|}
\hline DCMF & Petrimonas & Clostridiales $[\mathrm{O}]$ \\
Synergistaceae $[\mathrm{F}]$ & Lentimicrobiaceae $[\mathrm{F}]$ & Sphingomonas \\
Spirochaetaceae $[\mathrm{F}]$ & Geobacter & Other \\
Veillonellaceae $[\mathrm{F}]$ & Firmicutes $[\mathrm{P}]$ & \\
Desulfovibrio & Bacteroidetes $[\mathrm{C}]$ & \\
\hline
\end{tabular}

Fig. 3 Temporal shifts in the community composition of culture DFE with different substrates. Illumina $16 \mathrm{~S}$ rRNA amplicon sequencing was used to determine DFE community composition (left $y$-axis) at timepoints across the growth experiments amended with $\mathbf{A}$ DCM, B choline, $\mathbf{C}$ glycine betaine, and $\mathbf{D}$ methanol reported in Figs. 1 and 2. ASVs are reported down to genus level where possible, otherwise taxonomic level is indicated in the legend $([\mathrm{F}]=$ family,

Fig. 4 Morphology of DCMF. FISH microscopy images show DCMF cells stained red with the Cy3-labelled Dcm623 probe (A), all bacterial cells stained green with the 6-FAM-labelled Eub338i probe $(\mathbf{B})$, and the overlay of Cy3- and 6-FAMlabelling in these images $(\mathbf{C})$. The scale bars represent $10 \mu \mathrm{M}$.

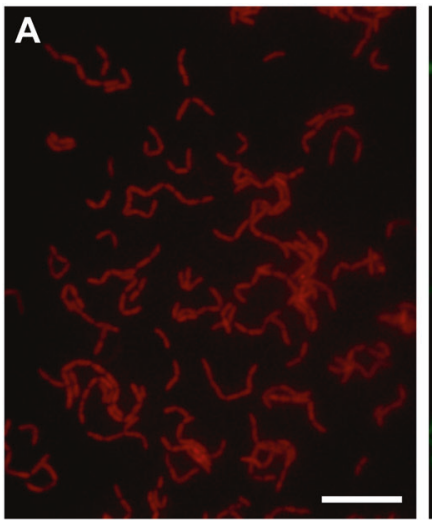

$[\mathrm{P}]=$ phylum, $[\mathrm{C}]=$ class, $[\mathrm{O}]=$ order). Reads with $<1 \%$ abundance were filtered out in QIIME2. Unassigned reads and ASVs consistently $<2 \%$ relative abundance were classed together as 'Other'. Substrate concentration (black circles, right $y$-axis) and a line connecting the mean substrate concentration at each time point is overlaid on the community composition graphs. These are aligned with the time points written on the $\mathrm{x}$-axis, not drawn to scale.
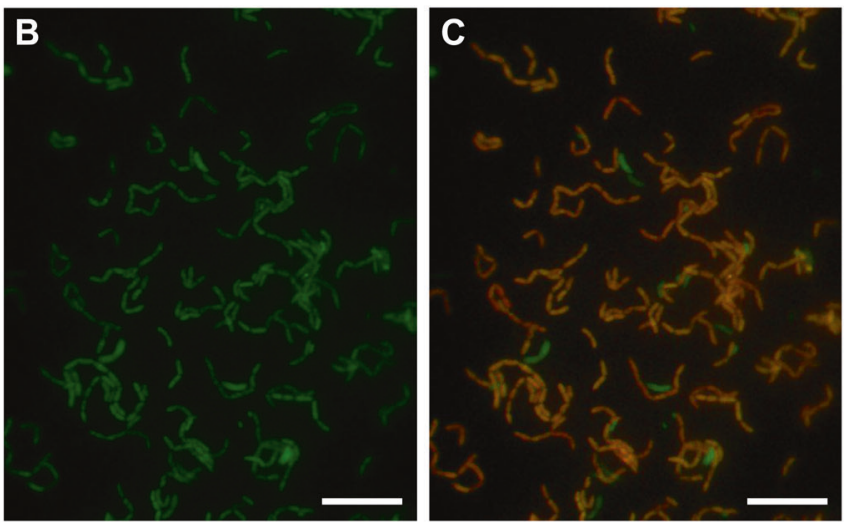

culture DFE were enriched to the exclusion of DCMF. This was achieved by dilution to extinction cultures on rich media amended with casamino acids, glucose, peptone, or yeast extract. These growth conditions variously enriched Bacillus, Desulfovibrio, Geobacter, Petrimonas, and Veillonellaceae, but not DCMF (Fig. S3A-D). Spirochaetaceae and Synergistaceae phylotypes did not grow on the tested rich media.
The community composition of the four DCMF-free enrichment cultures was considerably altered from the typical, DCM-amended DFE culture, as 16S rRNA gene amplicon sequencing revealed only one to five ASVs in each of the former, compared to $>10$ in the latter (Fig. S4A-D).

The DCMF-free cohabitant cultures were then tested for their ability to utilise DCM, choline, and glycine betaine. 
Fig. 5 Assimilation of carbon from ${ }^{13} \mathrm{C}$-labelled DCM and bicarbonate to form acetate. Cumulative $\left[{ }^{13} \mathrm{C}\right] \mathrm{DCM}$ consumption with concomitant acetate production $(\mathbf{A})$, the proportion of labelled and unlabelled acetate $(\mathbf{B})$, and the ${ }^{13} \mathrm{C}$ mass balance from $\left[{ }^{13} \mathrm{C}\right]$ DCM (C). Error bars represent standard deviation, $n=3$. Cumulative DCM consumption and acetate production in cultures amended with $\mathrm{H}^{13} \mathrm{CO}_{3}$ (D). Total (labelled and unlabelled) aqueous $\mathrm{HCO}_{3}{ }^{-}$is also shown (i.e. gaseous $\mathrm{CO}_{2}$ is not accounted for here). Values in (D) are from a single representative culture as all triplicates had similar dechlorination rates and product concentrations but began dechlorinating at different times. The proportion of labelled and unlabelled acetate $(\mathbf{E})$ and ${ }^{13} \mathrm{C}$ mass balance from $\mathrm{H}^{13} \mathrm{CO}_{3}{ }^{-}(\mathbf{F})$ is again shown. All pie charts represent the average of triplicate cultures at the final time point.

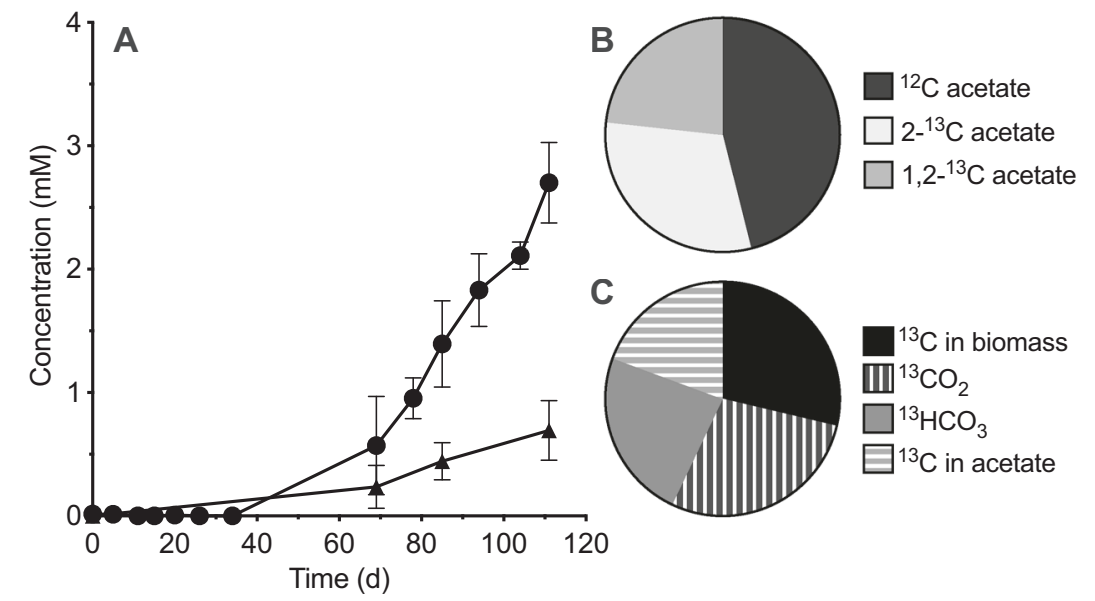

\begin{tabular}{ll}
$\rightarrow$ Total DCM consumed & $\prec{ }^{13}$ C-labelled bicarbonate \\
$\leftarrow$ Acetate produced & $\diamond$. Total bicarbonate \\
\hline
\end{tabular}

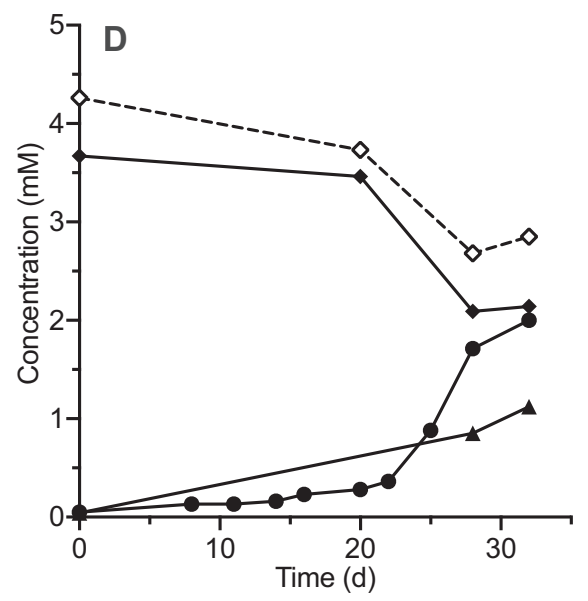

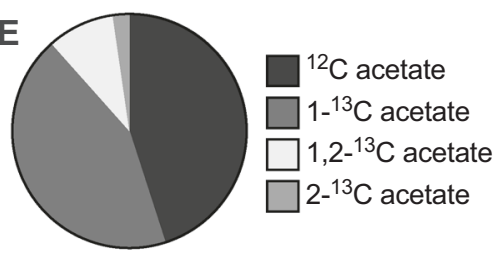

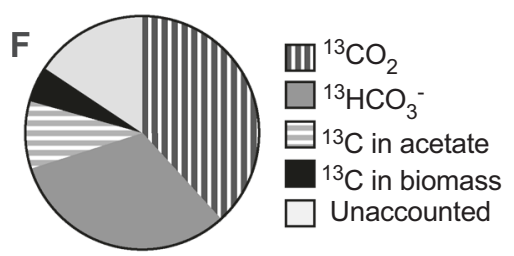

There was no significant substrate depletion in these cultures (Fig. S4E-H), and therefore no evidence of DCM, choline, or glycine betaine degradation by the Bacillus, Desulfovibrio, Geobacter, Petrimonas, or Veillonellaceae phylotypes in culture DFE.

\section{DCMF morphology}

FISH microscopy enabled selective visualisation of DCMF cells, which appeared rod-shaped and occurred singly or in chains (Fig. 4A). On average, DCMF cells were $1.69 \pm 0.27$ $\mu \mathrm{m}$ long and $0.64 \pm 0.12 \mu \mathrm{m}$ wide. FISH images confirmed that DCMF numerically dominated culture DFE during DCM dechlorination (Fig. 4C), congruent with community profiling results.

\section{DCMF is mixotrophic}

To ascertain the fate of DCM carbon, triplicate DFE cultures were amended with $\left[{ }^{13} \mathrm{C}\right] \mathrm{DCM}$. When $2700 \pm 328 \mu \mathrm{M}$ DCM had been consumed, $666 \pm 160 \mu \mathrm{M}$ of acetate was produced (Fig. 5A), of which $47.1 \pm 5.5 \%$ was unlabelled, $30.4 \pm 2.8 \%$ was methyl group labelled $\left(\left[2-{ }^{13} \mathrm{C}\right]\right.$ acetate $)$, and $22.5 \pm 4.3 \%$ was both methyl and carboxyl group labelled $\left(\left[1,2-{ }^{13} \mathrm{C}\right]\right.$ acetate; Fig. $\left.5 \mathrm{~B}\right) . \quad \mathrm{A}{ }^{13} \mathrm{C}$ mass balance was achieved by summing the measured concentrations of ${ }^{13} \mathrm{C}$ labelled carbon in acetate $(670 \pm 289 \mu \mathrm{M})$ and $\mathrm{H}^{13} \mathrm{CO}_{3}{ }^{-}$ $(815 \pm 120 \mu \mathrm{M})$ with the calculated concentrations of ${ }^{13} \mathrm{CO}_{2}$ in the flask headspace $(982 \pm 144 \mu \mathrm{M})$ and $\left[{ }^{13} \mathrm{C}\right]$ acetate equivalents in biomass $(994 \pm 121 \mu \mathrm{M}$; Fig. 5C, Table S4). This amounted to $128 \pm 8.2 \%$ recovery of the labelled carbon, indicating no unknown fate of DCM in culture DFE.

Analogous work was then carried out with unlabelled DCM in MOPS-buffered medium amended with ${ }^{13} \mathrm{C}$-labelled bicarbonate, showing that DCMF incorporated carbon from $\mathrm{CO}_{2}$ into the carboxyl group of acetate. The culture consumed $2000 \mu \mathrm{M}$ DCM and $2150 \pm 492 \mu \mathrm{M}{ }^{13} \mathrm{C}$ from bicarbonate. It produced $973 \pm 140 \mu \mathrm{M}$ acetate (Fig. 5D), of which $45.0 \pm$ $2.3 \%$ was unlabelled, $43.5 \pm 1.8 \%$ was labelled on the carboxyl group $\left(\left[1-{ }^{13} \mathrm{C}\right]\right.$ acetate), $2.2 \pm 1.3 \%$ was labelled on the methyl group, and $9.3 \pm 0.1 \%$ was labelled on both carbons (Fig. 5E). A mass balance indicated $84.5 \pm 7.0 \%$ recovery of 
Table 1 Average amino acid (AAI) identity table of DCMF and related bacteria from the Peptococcaceae family.

\begin{tabular}{|c|c|c|c|c|c|c|c|c|c|c|c|c|}
\hline Taxon & 1. & 2. & 3. & 4. & 5 . & 6. & 7. & 8. & 9. & 10. & 11. & 12. \\
\hline 1. $\mathrm{DCMF}^{*}$ & 100.0 & & & & & & & & & & & \\
\hline 2. Dehalobacterium formicoaceticum $\mathrm{DMC}^{*}$ & 66.5 & 100.0 & & & & & & & & & & \\
\hline 3. Thermincola potens $\mathrm{JR}$ & 55.2 & 54.7 & 100.0 & & & & & & & & & \\
\hline 4. Desulfosporosinus orientis DSM 765 & 54.1 & 53.8 & 53.6 & 100.0 & & & & & & & & \\
\hline 5. Desulfotomaculm nigrificans CO-1-SRB & 54.0 & 54.8 & 57.8 & 53.4 & 100.0 & & & & & & & \\
\hline 6. Pelotomaculum thermopropionicum SI & 54.0 & 53.3 & 58.3 & 52.0 & 61.1 & 100.0 & & & & & & \\
\hline 7. Desulfofarcimen acetoxidans DSM 771 & 54.0 & 53.3 & 56.3 & 53.1 & 59.5 & 60.1 & 100.0 & & & & & \\
\hline 8. Desulfitobacterium hafniense DCB-2 & 53.4 & 54.5 & 53.2 & 63.6 & 53.2 & 52.1 & 52.4 & 100.0 & & & & \\
\hline 9. Dehalobacter sp. CF & 53.3 & 56.1 & 52.5 & 58.2 & 52.0 & 51.5 & 52.6 & 58.5 & 100.0 & & & \\
\hline $\begin{array}{l}\text { 10. 'Candidatus Dichloromethanomonas } \\
\text { elyunquensis' RM* }\end{array}$ & 53.1 & 53.1 & 53.2 & 59.5 & 52.5 & 52.4 & 52.2 & 59.2 & 70.0 & 100.0 & & \\
\hline 11. Desulfitibacterium metallireducens DSM 15288 & 53.1 & 53.4 & 53.4 & 65.1 & 53.2 & 52.9 & 52.6 & 68.1 & 58.5 & 59.5 & 100.0 & \\
\hline 12. Syntrophpbotulus glycolicus DSM 8271 & 52.5 & 53.7 & 52.5 & 57.9 & 52.1 & 51.7 & 52.1 & 58.3 & 62.8 & 63.8 & 58.1 & 100.0 \\
\hline
\end{tabular}

Bacteria are listed in order of highest to lowest AAI to DCMF and only the species with the highest AAI value was taken from each genus. Dichloromethane-degrading bacteria are marked with an asterisk (*). Numbers in the header correspond to the taxa in the left-hand column.

the labelled carbon in acetate $(600 \pm 84.9 \mu \mathrm{M})$, the remaining $\mathrm{H}^{13} \mathrm{CO}_{3}{ }^{-}(2280 \pm 170 \mu \mathrm{M})$ and ${ }^{13} \mathrm{CO}_{2}(2740 \pm 204 \mu \mathrm{M})$, and DCMF biomass $(710 \pm 9.74 \mu \mathrm{M}$; Fig. 5F, Table S4).

\section{Phylogenetic analysis of DCMF}

Whole genome taxonomic analysis of DCMF with the GTDB-Tk identified its closest relative as Dehalobacterium formicoaceticum strain DMC, placing them together in the novel family taxon Dehalobacteriaceae (order Dehalobacteriales, class Dehalobacteriia, phylum Firmicutes). The GTDB re-classified a wide range of bacterial taxa based on its analysis pipeline, including splitting the traditional class of Clostridia (which includes the family Peptococcaceae) into a variety of more specific, monophyletic classes [33], and hence this classification is equivalent to the assignation of family Peptococcaceae previously suggested for DCMF [24].

DCMF had $77.19 \%$ ANI to its closest relative, D. formicoaceticum strain DMC. Given that ANI offers robust resolution primarily above $80 \%$ values [61], AAI analysis was instead carried out to evaluate genomic distance between DCMF and its closest relatives. D. formicoaceticum was again confirmed as the closest relative to DCMF (AAI value 66.54\%), with ' $\mathrm{Ca}$. Dichloromethanomonas elyunquensis' and other members of the Peptococcaceae all considerably lower (Table 1).

\section{Discussion}

\section{The DFE community}

DCMF is a novel candidate species present in enrichment culture DFE, which has been maintained with DCM as sole external energy source for 5 years and at least 20 consecutive transfers [24]. Of the five cohabiting phylotypes previously reported in culture DFE based on 16S rRNA genes identified from PacBio sequencing data [24], four remained amongst the most abundant in the present work (Desulfovibrio, Lentimicrobiaceae, Spirochaetaceae, and Synergistaceae), while one was no longer detected (Ignavibacteria). In combination with the similar community profiles observed across four different substrates, this suggests that culture DFE is a long-term stable-state community.

Illumina amplicon sequencing, FISH microscopy, and qPCR all supported the previous observation [24] of DCMF as the dominant organism in culture DFE during substrate consumption, and linked growth of DCMF to depletion of DCM, methanol, choline, and glycine betaine. Attempts to generate an axenic culture of DCMF have been unsuccessful, similar to the DCM-mineralising bacterium ' $\mathrm{Ca}$. Dichloromethanomonas elyunquensis' in culture RM $[19,23]$. How the cohabiting organisms in both cultures persist despite numerous transfers and addition of only a simple chlorinated compound (DCM) to minimal, anaerobic medium is a question of interest. While hydrogenotrophic acetogens and methanogens form major sub-populations in culture RM [18, 19, 23], culture DFE is non-methanogenic [24] and was unable to grow on $\mathrm{H}_{2}+\mathrm{CO}_{2}$ alone.

Five of the 12 taxa in culture DFE were categorically excluded from being primary metabolisers of DCM, choline, and glycine betaine when tested in the absence of DCMF (Fig. S4). Spirochaetaceae and Synergistaceae phylotypes, which comprised a significant proportion of the DCM- and methanol-amended communities at various timepoints, respectively, could not be enriched to the exclusion of DCMF. However, their relative abundance 


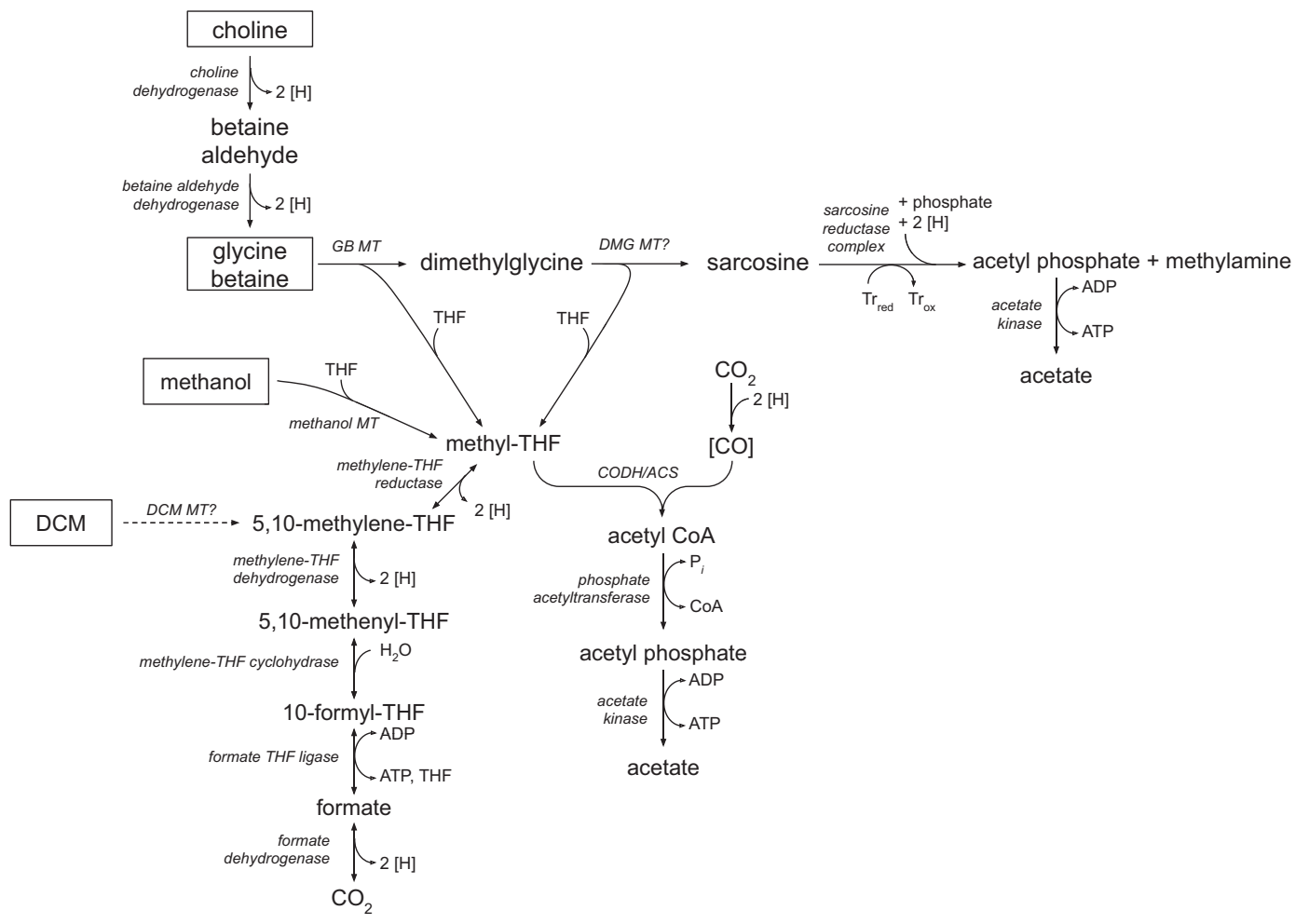

Fig. 6 Proposed model for metabolism of DCM, methanol, and quaternary amines by DCMF. The Wood-Ljungdahl pathway is central to transformation of all substrates into acetate. Proteins (with the exception of that catalysing the putative transformation of DCM to $\mathrm{CH}_{2}=\mathrm{FH}_{2}$, indicated by dotted arrow) are all identified in the DCMF

during growth on all substrates diminished relative to DCMF, suggesting that it is unlikely they are primary consumers of these substrates. Instead, the timing of the changes in relative abundance and known substrate range of major phylotypes in culture DFE suggest that the cohabiting bacteria use cellular detritus resulting from expired DCMF cells as an energy source (i.e. necromass fermentation; Supplementary Discussion).

\section{The role of the WLP in DCM metabolism}

Amongst anaerobic DCM-dechlorinating bacteria, DCMF is unique in producing solely acetate as an end product (Fig. 1A). D. formicoaceticum produced formate and acetate in a 2:1 molar ratio [15], while ' $\mathrm{Ca}$. Dichloromethanomonas elyunquensis' completely mineralised DCM to $\mathrm{H}_{2}, \mathrm{CO}_{2}$, and $\mathrm{Cl}^{-}$[23]. The latter organism is unique in also encoding and expressing reductive dehalogenases during growth with DCM [19, 20]. Despite these differences, both organisms utilise the WLP for DCM metabolism $[15,20,23]$ as is likely the case with DCMF. Removal of bicarbonate from the culture medium precluded DCM dechlorination and ensuing work with ${ }^{13} \mathrm{C}$-labelled DCM and bicarbonate demonstrated that DCMF is genome and listed in Table S5. CODH/ACS carbon monoxide dehydrogenase/acetyl-CoA synthase, DCM dichloromethane, DMG dimethylglycine, GB glycine betaine, MT methyltransferase, ox oxidised, red reduced, THF tetrahydrofolate, Tr thioredoxin.

mixotrophic, i.e. assimilates carbon from both DCM and $\mathrm{CO}_{2}$, similar to D. formicoaceticum [23].

These experiments also provided compelling evidence for the transformation of DCM to a WLP intermediate, most likely methylene-tetrahydrofolate $\left(\mathrm{CH}_{2}=\mathrm{FH}_{2} ; \mathrm{Eq} .1\right)$, as has previously been demonstrated in cell-free extracts of $D$. formicoaceticum [35]. In culture DFE, the production of $\mathrm{H}^{13} \mathrm{CO}_{3}{ }^{-}$from $\left[{ }^{13} \mathrm{C}\right] \mathrm{DCM}$ suggested that $\mathrm{CH}_{2}=\mathrm{FH}_{2}$ is disproportionated into the WLP where it is oxidised to $\mathrm{HCO}_{3}{ }^{-}$(Eq. 2, Fig. 6, Table S5). The electrons released could then reduce the remaining $\mathrm{CH}_{2}=\mathrm{FH}_{2}$ into the methyl group of acetate (Eq. 3). However, the production of unlabelled acetate $(47 \%)$ indicates that the excess unlabelled $\mathrm{HCO}_{3}{ }^{-}(30 \mathrm{mM})$ in the medium is an alternative electron acceptor to $\mathrm{CH}_{2}=\mathrm{FH}_{2}$ for acetogenesis (Eq. 4; Fig. 6). The reduction of $\mathrm{HCO}_{3}{ }^{-}$to acetate requires twice as many electrons for acetate synthesis than $\mathrm{CH}_{2}=\mathrm{FH}_{2}$ (i.e. eight vs. four). Taking this ratio into account, along with $\sim 1: 1$ ratio of unlabelled to labelled acetate suggests that $\sim 67 \%$ of electrons derived from DCM oxidation were directed toward $\mathrm{HCO}_{3}{ }^{-}$reduction and $33 \%$ to $\mathrm{CH}_{2}=\mathrm{FH}_{2}$ reduction. Acetogenesis from both $\mathrm{HCO}_{3}{ }^{-}$and $\mathrm{CH}_{2}=\mathrm{FH}_{2}$ reduction may allow for greater carbon assimilation and energy production, contributing to DCMF cell yields one 
order of magnitude higher than those previously reported for the anaerobic DCM degraders D. formicoaceticum and 'Ca. Dichloromethanomonas elyunquensis' [23].

$$
\begin{aligned}
& 4 \mathrm{CH}_{2} \mathrm{Cl}_{2}+4 \mathrm{FH}_{4} \rightarrow 4 \mathrm{CH}_{2}=\mathrm{FH}_{2}+8 \mathrm{H}^{+}+8 \mathrm{Cl}^{-} \\
& 3 \mathrm{CH}_{2}= \mathrm{FH}_{2}+9 \mathrm{H}_{2} \mathrm{O} \rightarrow 3 \mathrm{HCO}_{3}^{-}+12 \mathrm{e}^{-} \\
&+3 \mathrm{FH}_{4}+15 \mathrm{H}^{+} \\
& \mathrm{CH}_{2}= \mathrm{FH}_{2}+4 \mathrm{e}^{-}+\mathrm{HCO}_{3}^{-}+4 \mathrm{H}^{+} \rightarrow \mathrm{CH}_{3} \mathrm{COO}^{-} \\
&+\mathrm{H}_{2} \mathrm{O}+\mathrm{FH}_{4} \\
& 2 \mathrm{HCO}_{3}^{-}+9 \mathrm{H}^{+}+8 \mathrm{e}^{-} \rightarrow \mathrm{CH}_{3} \mathrm{COO}^{-}+4 \mathrm{H}_{2} \mathrm{O}
\end{aligned}
$$

The production of $\left[1,2-{ }^{13} \mathrm{C}\right]$ acetate from $\left[{ }^{13} \mathrm{C}\right] \mathrm{DCM}$ is consistent with the reduction of $\mathrm{H}^{13} \mathrm{CO}_{3}{ }^{-}$outlined above. However, the proportion (22.5\%) was surprisingly high, given the relatively small contribution that labelled $\mathrm{H}^{13} \mathrm{CO}_{3}{ }^{-}$from $2.7 \mathrm{mM}\left[{ }^{13} \mathrm{C}\right] \mathrm{DCM}$ would make to the $30 \mathrm{mM}$ unlabelled $\mathrm{HCO}_{3}{ }^{-}$present in the culture medium. It is possible that colocalisation of WLP proteins in the cytoplasm may cause the reduction of $\mathrm{H}^{13} \mathrm{CO}_{3}{ }^{-}$at a higher ratio than expected (i.e. 9\%). Studies with $\left[{ }^{13} \mathrm{C}\right] \mathrm{DCM}$ in $D$. formicoaceticum detected the ${ }^{13} \mathrm{C}$ label solely in the methyl group of acetate $\left(\left[2-{ }^{13} \mathrm{C}\right]\right.$ acetate), congruent with DCM oxidation stopping at formate [23, 35], while studies with another Dehalobacterium species in mixed culture that was capable of formate oxidation similarly detected $\left[1,2-{ }^{13} \mathrm{C}\right]$ acetate [36].

DFE cultures amended with unlabelled DCM and ${ }^{13} \mathrm{C}$ labelled $\mathrm{HCO}_{3}{ }^{-}$in MOPS-buffered medium produced an analogous proportion of $\left[1-{ }^{13} \mathrm{C}\right]$ acetate. A similar proportion of acetate $(45.0 \%)$ to that observed in the $\left[{ }^{13} \mathrm{C}\right] \mathrm{DCM}$ work was unlabelled, in this case evidently formed using unlabelled $\mathrm{HCO}_{3}{ }^{-}$produced from DCM. Thus, the ${ }^{13} \mathrm{C}-$ labelling experiments support the hypothesis that DCM metabolism involves the WLP and are consistent with the oxidation of formate to $\mathrm{HCO}_{3}{ }^{-}$. As an exogenous supply of formate was unable to stimulate growth of culture DFE, DCMF alone is likely responsible for formate metabolism, which contrasts with the inability of $D$. formicoaceticum to further transform this metabolite [15]. The production of $\mathrm{HCO}_{3}{ }^{-}$from formate balances with its uptake during acetogenesis, congruent with a net flux of approximately zero, leading to the proposal that DCM is transformed as per Eq. 5.

$2 \mathrm{CH}_{2} \mathrm{Cl}_{2}+2 \mathrm{H}_{2} \mathrm{O} \rightarrow \mathrm{CH}_{3} \mathrm{COO}^{-}+5 \mathrm{H}^{+}+4 \mathrm{Cl}^{-}$

\section{Metabolism of non-chlorinated substrates}

DCMF is the first anaerobic DCM-degrading bacterium that is also capable of metabolising non-halogenated substrates.
A genome-based metabolic model previously suggested that the abundance of MttB superfamily methyltransferases (named for their founding member, a trimethylamine:corrinoid methyltransferase) encoded by DCMF may permit growth on methylated amines and/or glycines [24]. While DCMF was unable to metabolise trimethylamine, growth was observed with glycine betaine and the closely related compound choline. Both compounds are quaternary amines with significant environmental roles. Glycine betaine is an osmoprotectant widely used by bacteria [37-39], marine algae [40], marine invertebrates [41], plants [42], and some vertebrates [43]. It is also an important source of nitrogen, comprising up to $20 \%$ of the total nitrogen in hypersaline environments [44]. Choline is typically more abundant, albeit as a part of larger molecules including eukaryotic phospholipids, and can be converted to glycine betaine by a near ubiquitous pathway in soil and water environments [45].

Accordingly, DCMF encodes both the choline dehydrogenase (Ga0180325_11215) and betaine aldehyde dehydrogenase (Ga0180325_114191) required for this transformation to glycine betaine. Based on the stoichiometry of observed end products, growth on putative pathway intermediates, and genomic information, we propose that DCMF likely stepwise demethylates glycine betaine to dimethylglycine and then sarcosine (methylglycine), which is then reductively cleaved to form acetate (via acetylphosphate) and monomethylamine (Supplementary Discussion, Fig. 6 and Table S5). The electron equivalents produced from demethylation can be used for additional reduction of $\mathrm{CO}_{2}$ to acetate via the WLP, as well as the reductive cleavage of sarcosine. This combination of demethylation and reductive cleavage has previously only been observed in Sporomusa spp. [46, 47] and is a novel metabolic pathway within the Peptococcaceae family. A theoretical energy balance of the product formation and DCMF cell yield suggested that no other organisms in culture DFE were involved in quaternary amine metabolism (Supplementary Discussion).

The DCMF genome also encodes a number of methanol methyltransferases, which are likely utilised for transformation of methanol into $\mathrm{CH}_{2}=\mathrm{FH}_{4}$ prior to its entry into the WLP and transformation to acetate (Supplementary Discussion, Fig. 6 and Table S5).

\section{Environmental significance}

The ability of DCMF to utilise choline, glycine betaine, and methanol suggests that its environmental relevance extends beyond DCM contaminated sites. Coastal salt marshes and intertidal mudflats represent significant sources of methane from the demethylation of trimethylamine, which is in turn derived from quaternary amines [48-50]. Both 
trimethylamine and methanol are non-competitive methane precursors, which may allow large methanogen populations to develop in environments where sulphate reduction would typically dominate [51, 52]. Indeed, trimethylamine is responsible for $60-90 \%$ of methane production in coastal salt marshes and intertidal sediments [49, 51]. The transformation of quaternary amines to monomethylamine by DCMF provides a pathway of lower methanogenic potential that could operate in coastal subsurface environments. DCMF does create acetate as a major end product, which can be utilised by acetoclastic methanogens. However, unlike methylated amines, methanogens have to compete with more thermodynamically favourable processes such as sulphate reduction for this substrate.

Furthermore, DCM has recently also been recognised as a potent greenhouse gas with ozone-depleting potential [7], and oxygenated hydrocarbons such as methanol can influence atmospheric ozone formation through reactions with nitrous oxides [53]. Therefore, although DCM, methanol, and quaternary amines are seemingly disparate substrates, they are closely linked to the atmospheric flux of climateactive gasses from anoxic, subsurface environments. This is both via the direct influence that DCM and methanol can have on ozone, and the indirect influence of quaternary amines on the flux of methylated amines and methane.

Within an environmental context, 16S rRNA sequences closely related to DCMF have previously been identified at an organochlorine-contaminated site in France [54]. The DCMF ASV had a greater relative abundance in samples taken from the more highly contaminated source (up to $9.78 \%$ ) and plume (up to $14.7 \%$ ) sampling wells, compared to the plume boundary $(<0.01 \%)$ [54]. A BLAST search of the NCBI nucleotide (nr) sequence database also revealed closely related sequences ( $>90 \%$ nucleotide identity) to the DCMF 16S rRNA gene from a range of environmental samples including organochlorine-contaminated aquifers, mud volcanoes, wastewater treatment systems, anaerobic bioreactors, mammalian and insect guts (Fig. S5). This indicates that DCMF and similar phylotypes are widely distributed in the environment, with potential to affect DCM dechlorination and flux of climate-active compounds on a larger scale.

\section{Provisional classification of DCMF as a novel genus and species}

The family Peptococcaceae (order Clostridiales, class Clostridia) is a physiologically and phylogenetically diverse group of Gram-positive anaerobic bacteria [55-57]. Many of the initial members were isolated from human samples, but other taxa from environmental samples have since been added [57]. The physiological diversity of the family includes chemoorganotrophic, chemolithoheterotrophic, chemolithoautotrophic taxa [57] capable of both fermentative (e.g. the DCM-fermenting genus Dehalobacterium) [15] and respiratory metabolism (e.g. the organochlorinerespiring genus Dehalobacter) [58].

We previously reported that $16 \mathrm{~S}$ rRNA gene phylogeny and analysis of a restricted set of universal and ribosomal proteins determined that DCMF is most closely related to $D$. formicoaceticum within the family Peptococcaceae, although it likely represented a novel genus [24]. This was further confirmed in the present work via whole genome analysis. AAI analysis also supported placement of DCMF in a novel genus based on a suggested $\sim 70 \%$ AAI threshold [59], although DCMF and D. formicoaceticum $(66.54 \%$ AAI; Table 1) surpass a more recently proposed $55-60 \%$ AAI threshold [34]. However, the physiological information presented here distinguishes DCMF from the sole representative of the genus Dehalobacterium, which has thus far only proved capable of growth on DCM [15]. DCMF also harbours a significantly larger genome than $D$. formicoaceticum $(6.44 \mathrm{Mb}$ for the former, $3.77 \mathrm{Mb}$ for the latter) [22], which may account for its wider substrate range.

DCMF appears to be an anaerobic methylotroph, capable of metabolising a unique range of one-carbon compounds (DCM, methanol) or substrates from which it can utilise methyl groups (choline, glycine betaine, dimethylglycine, sarcosine). Thus, genomic, phylogenetic, and physiological evidence supports the placement of DCMF within a novel genus in the family Peptococcaceae. As DCMF is not yet represented in pure culture despite intensive efforts to isolate the organism, we propose it be classified in the category Candidatus $[60,61]$ and named 'Candidatus Formimonas warabiya'.

\section{Description of 'Candidatus Formimonas warabiya'}

(Form.i.mon'as. L. neut. adj. formicum relating to formic acid or, more generally, one-carbon compounds; Gr. fem. n. monas a monad, unit; N.L. fem. n. Formimonas the onecarbon utilising unit; war.a.bi'ya N.L. neut. n. warabiya the Dharawal name for the area between Botany Bay and Bunnerong, honouring the Traditional Custodians of the land where this bacterium was sampled from. Permission was granted from the Dharawal Language Program research group for use of this word as the species name.)

Strictly anaerobic. Utilises DCM, methanol, choline, glycine betaine, dimethylglycine as sole sources of electrons. Can also utilise the electron donor and acceptor pair $\mathrm{H}_{2}$ and sarcosine. Utilises organic (the aforementioned substrates) and inorganic $\left(\mathrm{CO}_{2}\right)$ carbon sources. The primary product is acetate; monomethylamine is also produced from choline, glycine betaine, dimethylglycine, and sarcosine $+\mathrm{H}_{2}$. Cells are rod shaped $(1.69 \times 0.27 \mu \mathrm{m})$. The source of inoculum was contaminated sediment from the Botany 
Sands aquifer, adjacent to Botany Bay, Sydney, Australia. The type material is the finished genome of 'Candidatus Formimonas warabiya' strain DCMF, which is $6.44 \mathrm{Mb}$ and has a $\mathrm{G}+\mathrm{C}$ content of $46.4 \%$ (GenBank accession number CP017634.1; IMG genome ID 2718217647).

Acknowledgements Thanks to Dr. Valentina Wong for her initial culturing assistance. SH was supported by an Australian Government Research Training Program Scholarship.

\section{Compliance with ethical standards}

Conflict of interest The authors declare that they have no conflict of interest.

Publisher's note Springer Nature remains neutral with regard to jurisdictional claims in published maps and institutional affiliations.

Open Access This article is licensed under a Creative Commons Attribution 4.0 International License, which permits use, sharing, adaptation, distribution and reproduction in any medium or format, as long as you give appropriate credit to the original author(s) and the source, provide a link to the Creative Commons license, and indicate if changes were made. The images or other third party material in this article are included in the article's Creative Commons license, unless indicated otherwise in a credit line to the material. If material is not included in the article's Creative Commons license and your intended use is not permitted by statutory regulation or exceeds the permitted use, you will need to obtain permission directly from the copyright holder. To view a copy of this license, visit http://creativecommons. org/licenses/by/4.0/.

\section{References}

1. Shestakova M, Sillanpää M. Removal of dichloromethane from ground and wastewater: a review. Chemosphere 2013;93:1258-67.

2. Gribble GW. Naturally occurring organohalogen compounds: a comprehensive update. In: Progress in the Chemistry of Organic Natural Products. Volume 91. Vienna, Austria: Springer Vienna; 2010. p. 12-3.

3. Carpenter LJ, Reimann S. Update on Ozone-Depleting Substances (ODSs) and Other Gases of Interest to the Montreal Protocol. In: Engel A, Montzka SA, editors. Scientific Assessment of Ozone Depletion: 2014. Global Ozone Research and Monitoring Project Report No 55. Geneva, Switzerland: World Meteotological Organization; 2014.

4. Hossaini R, Chipperfield MP, Montzka SA, Rap A, Dhomse S, Feng W. Efficiency of short-lived halogens at influencing climate through depletion of stratospheric ozone. Nat Geosci. 2015;8:186-90.

5. Hossaini R, Chipperfield MP, Saiz-Lopez A, Harrison JJ, Von Glasow R, Sommariva R, et al. Growth in stratospheric chlorine from short-lived chemicals not controlled by the Montreal Protocol. Geophys Res Lett. 2015;42:4573-80.

6. Leedham Elvidge EC, Oram DE, Laube JC, Baker AK, Montzka SA, Humphrey $\mathrm{S}$, et al. Increasing concentrations of dichloromethane, $\mathrm{CH}_{2} \mathrm{Cl}_{2}$, inferred from CARIBIC air samples collected 1998-2012. Atmos Chem Phys 2015;15:1939-58.

7. Hossaini R, Chipperfield MP, Montzka SA, Leeson AA, Dhomse SS, Pyle JA. The increasing threat to stratospheric ozone from dichloromethane. Nat Commun. 2017;8:15962.

8. International Agency for Research on Cancer. Dichloromethane. In: IARC monograph on the evaluation of the carcinogenic risk of chemicals to humans. 41st ed. Lyon, France: International Agency for Research on Cancer; 1986. p. 43-85.

9. Agency for Toxic Substances and Disease Registry. Toxicological profile for methylene chloride. Atlanta, Georgia: Agency for Toxic Substances and Disease Registry; 2000.

10. Stuckey DC, Owen WF, McCarty PL, Parkin GF. Anaerobic toxicity evaluation by batch and semi-continuous assays. J Water Pollut Control Fed. 1980;52:720-9.

11. Kanazawa S, Filip Z. Effects of trichloroethylene, tetrachloroethylene and dichloromethane on enzymatic activities in soil. Appl Microbiol Biotechnol. 1986;25:76-81.

12. Yu Z, Smith GB. Inhibition of methanogenesis by C1- and C2polychlorinated aliphatic hydrocarbons. Environ Toxicol Chem. 2000;19:2212-7.

13. La Roche SD, Leisinger T. Sequence analysis and expression of the bacterial dichloromethane dehalogenase structural gene, a member of the glutathione-S-transferase supergene family. J Bacteriol. 1990;172:164-71.

14. Muller EEL, Bringel F, Vuilleumier S. Dichloromethane-degrading bacteria in the genomic age. Res Microbiol. 2011;162:870-6.

15. Mägli A, Wendt $M$, Leisinger T. Isolation and characterization of Dehalobacterium formicoaceticum gen. nov. sp. nov., a strictly anaerobic bacterium utilizing dichloromethane as source of carbon and energy. Arch Microbiol. 1996;166:101-8.

16. Lee M, Low A, Zemb O, Koenig J, Michaelsen A, Manefield M. Complete chloroform dechlorination by organochlorine respiration and fermentation. Environ Microbiol. 2012;14:883-94.

17. Justicia-Leon SD, Ritalahti KM, Mack EE, Löffler FE. Dichloromethane fermentation by a Dehalobacter sp. in an enrichment culture derived from pristine river sediment. Appl Environ Microbiol. 2012;78:1288-91.

18. Trueba-Santiso A, Parladé E, Rosell M, Lliros M, Mortan SH, Martínez-Alonso M, et al. Molecular and carbon isotopic characterization of an anaerobic stable enrichment culture containing Dehalobacterium sp. during dichloromethane fermentation. Sci Total Environ. 2017;581-582:640-8.

19. Kleindienst $S$, Higgins SA, Tsementzi D, Chen G, Konstantinidis KT, Mack EE, et al. 'Candidatus Dichloromethanomonas elyunquensis' gen. nov., sp. nov., a dichloromethane-degrading anaerobe of the Peptococcaceae family. Syst Appl Microbiol. 2017;40:150-9.

20. Kleindienst S, Chourey K, Chen G, Murdoch RW, Higgins SA, Iyer $\mathrm{R}$, et al. Proteogenomics reveals novel reductive dehalogenases and methyltransferases expressed during anaerobic dichloromethane metabolism. Appl Environ Microbiol. 2019;85:1-16.

21. Kleindienst S, Higgins SA, Tsementzi D, Konstantinidis KT, Mack EE, Löffler FE. Draft genome sequence of a strictly anaerobic dichloromethane-degrading bacterium. Genome Announc. 2016;4:e0037-16.

22. Chen G, Murdoch RW, Mack EE, Seger ES, Löffler FE. Complete genome sequence of Dehalobacterium formicoaceticum strain DMC, a strictly anaerobic dichloromethane-degrading bacterium. Genome Announc. 2017;5:18-9.

23. Chen G, Fisch AR, Gibson CM, Erin Mack E, Seger ES, Campagna SR, et al. Mineralization versus fermentation: evidence for two distinct anaerobic bacterial degradation pathways for dichloromethane. ISME J. 2020;14:959-70.

24. Holland SI, Edwards RJ, Ertan H, Wong YK, Russell TL, Deshpande NP, et al. Whole genome sequencing of a novel, dichloromethane-fermenting Peptococcaceae from an enrichment culture. PeerJ 2019;7:e7775.

25. Villas-Bôas SG, Delicado DG, Åkesson M, Nielsen J. Simultaneous analysis of amino and nonamino organic acids as methyl chloroformate derivatives using gas chromatography-mass spectrometry. Anal Biochem. 2003;322:134-8.

26. Maeda H, Fujimoto C, Haruki Y, Maeda T, Kokeguchi S, Petelin $\mathrm{M}$, et al. Quantitative real-time PCR using TaqMan and SYBR 
Green for Actinobacillus actinomycetemcomitans, Porphyromonas gingivalis, Prevotella intermedia, tet $Q$ gene and total bacteria. FEMS Immunol Med Microbiol. 2003;39:81-6.

27. Caporaso JG, Kuczynski J, Stombaugh J, Bittinger K, Bushman FD, Costello EK, et al. QIIME allows analysis of high- throughput community sequencing data. Nat Methods. 2010;7:335-6.

28. Callahan BJ, McMurdie PJ, Rosen MJ, Han AW, Johnson AJA, Holmes SP. DADA2: High-resolution sample inference from Illumina amplicon data. Nat Methods. 2016;13:581-3.

29. Ludwig W, Strunk O, Westram R, Richter L, Meier H, Yadhukumar A, et al. ARB: A software environment for sequence data. Nucleic Acids Res. 2004;32:1363-71.

30. Amann RI, Binder BJ, Olson RJ, Chisholm SW, Devereux R, Stahl DA. Combination of 16S rRNA-targeted oligonucleotide probes with flow cytometry for analyzing mixed microbial populations. Appl Environ Microbiol. 1990;56:1919-25.

31. Ferrari BC, Winsley T, Gillings M, Binnerup S. Cultivating previously uncultured soil bacteria using a soil substrate membrane system. Nat Protoc. 2008;3:1261-9.

32. Roller C, Wagner M, Amann R, Ludwig W, Schleifer K-H. In situ probing of Gram-positive bacteria with high DNA G+C content using 23S rRNA-targeted oligonucleotides. Microbiology 1994; 140:2849-58.

33. Chaumeil P-A, Mussig AJ, Hugenholtz P, Parks DH. GTDB-Tk: a toolkit to classify genomes with the Genome Taxonomy Database. Bioinformatics. 2019. https://doi.org/10.1093/bioinformatics/btz848.

34. Rodriguez-R LM, Konstantinidis KT. Bypassing cultivation to identify bacterial species. Microbe. 2014;9:111-7.

35. Mägli A, Messmer M, Leisinger T. Metabolism of dichloromethane by the strict anaerobe Dehalobacterium formicoaceticum. Appl Environ Microbiol. 1998;64:646-50.

36. Trueba-Santiso A, Fernández-Verdejo D, Marco-Rius I, SoderWalz JM, Casabella O, Vicent T, et al. Interspecies interaction and effect of co-contaminants in an anaerobic dichloromethanedegrading culture. Chemosphere. 2020;240:124877.

37. Galinski EA, Trüper HG. Betaine, a compatible solute in the extremely halophilic phototrophic bacterium Ectothiorhodospira halochloris. FEMS Microbiol Lett. 1982;13:357-60.

38. Imhoff JF. Osmoregulation and compatible solutes in eubacteria. FEMS Microbiol Rev. 1986;39:57-66.

39. Csonka LN. Physiological and genetic responses of bacteria to osmotic stress. Microbiol Rev. 1989;53:121-47.

40. Blunden G, Gordon SM, McLean WFH, Guiry MD. The distribution and possible taxonomic significance of quaternary ammoniun and other Dragendorff-positive compounds in some genera of marine algae. Bot Mar. 1982;XXV:536-67.

41. Beers JR. The species distribution of some naturally occurring quaternary ammonium compounds. Comp Biochem Physiol. 1967;21:11-21.

42. Larher F, Jolivet Y, Briens U, Goas U. Osmoregulation in higher plants halophytes: organic nitrogen accumulation in glycine, betaine, and proline during the growth of Aster tripolinum and Sueda macrocarpa under saline conditions. Plant Sci Lett. 1982; 24:201-10.

43. Yancey PH, Clark ME, Hand SC, Bowlus RD, Somero GN. Living with water stress: evolution of osmolyte systems. Science. $1982 ; 217: 1214-22$
44. King GM. Methanogenesis from methylated amines in a hypersaline algal mat. Appl Environ Microbiol. 1988;54:130-6.

45. Wargo MJ. Homeostasis and catabolism of choline and glycine betaine: lessons from Pseudomonas aeruginosa. Appl Environ Microbiol. 2013;79:2112-20.

46. Möller B, Oßmer R, Howard BH, Gottschalk G, Hippe H. Sporomusa, a new genus of gram-negative anaerobic bacteria including Sporomusa sphaeroides spec. nov. and Sporomusa ovata spec. nov. Arch Microbiol. 1984;139:388-96.

47. Visser M, Pieterse MM, Pinkse MWH, Nijsse B, Verhaert PDEM, de Vos WM, et al. Unravelling the one-carbon metabolism of the acetogen Sporomusa strain An4 by genome and proteome analysis. Environ Microbiol. 2016;18:2843-55.

48. Jameson E, Stephenson J, Jones H, Millard A, Kaster A-K, Purdy $\mathrm{KJ}$, et al. Deltaproteobacteria (Pelobacter) and Methanococcoides are responsible for choline-dependent methanogenesis in a coastal saltmarsh sediment. ISME J 2019;13:277-89.

49. King GM. Metabolism of trimethylamine, choline, and glycine betaine by sulfate-reducing and methanogenic bacteria in marine sediments. Appl Environ Microbiol. 1984;48:719-25.

50. King GM. Distribution and metabolism of quaternary amines in marine sediments. In: Blackburn $\mathrm{TH}$, Soorensen J, editors. Nitrogen Cycling in Coastal Marine Environments. Berkley, CA: Wiley; 1988. p. 143-73.

51. Oremland RS, Marsh LM, Polcin S. Methane production and simultaneous sulphate reduction in anoxic, salt marsh sediments. Nature. 1982;296:143-5.

52. Oremland RS, Polcin S. Methanogenesis and sulfate reduction: competitive and noncompetitive substrates in estuarine sediments. Appl Environ Microbiol. 1982;44:1270-6.

53. Finlayson-Pitts BJ, Pitts NJJ. Chemistry of the upper and lower atmosphere. San Diego, CA: Academic Press; 2000.

54. Hermon L, Denonfoux J, Hellal J, Joulian C, Ferreira S, Vuilleumier $\mathrm{S}$, et al. Dichloromethane biodegradation in multi-contaminated groundwater: insights from biomolecular and compound-specific isotope analyses. Water Res. 2018;142:217-26.

55. Rogosa M. Peptococcaceae, a new family to include the Grampositive, anaerobic cocci of the genera Peptococcus, Peptostreptococcus, and Ruminococcus. Int J Syst Bacteriol. 1971;21:234-7.

56. Ezaki T. Peptococcaceae. In: Bergey's Manual of Systematics of Archaea and Bacteria. Wiley; 2015.

57. Stackebrandt E. The Emended Family Peptococcaceae and Description of the Families Desulfitobacteriaceae, Desulfotomaculaceae, and Thermincolaceae. In: Rosenberg E, DeLong EF, Lory S, Stackebrandt E, Thompson F, editors. The Prokaryotes. Berlin, Heidelberg: Springer Berlin Heidelberg; 2014. p. 285-90.

58. Maillard J, Holliger C. The genus Dehalobacter. In: Adrian L, Löffler FE, editors. Organohalide-Respiring Bacteria. Berlin Heidelberg: Springer; 2016. p. 153-72.

59. Konstantinidis KT, Tiedje JM. Prokaryotic taxonomy and phylogeny in the genomic era: advancements and challenges ahead. Curr Opin Microbiol. 2007;10:504-9.

60. Murray RGE, Stackebrandt E. Taxonomic note: implementation of the provisional status Candidatus for incompletely described procaryotes. Int J Syst Bacteriol. 1995;45:186-7.

61. Parker CT, Tindall BJ, GM Garrity. International code of nomenclature of prokaryotes. Int J Syst Evol Microbiol. 2019;69: S1-111. 